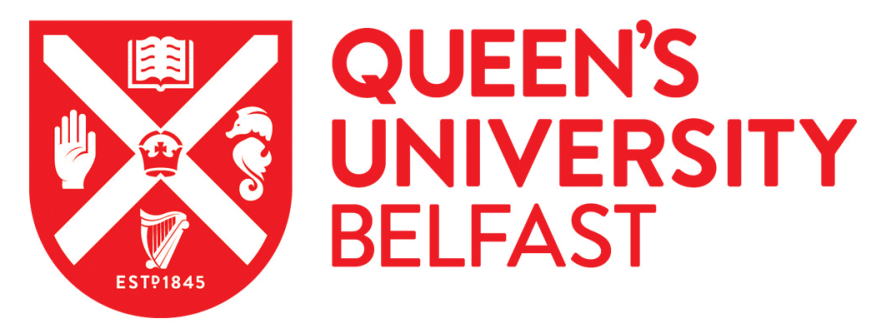

\title{
The association between glucose lowering drug use and mortality among breast cancer patients with type 2 diabetes.
}

\author{
Vissers, P. A. J., Cardwell, C. R., van de Poll-Franse, L. V., Young, I. S., Pouwer, F., \& Murray, L. J. (2015). The \\ association between glucose lowering drug use and mortality among breast cancer patients with type 2 diabetes. \\ Breast Cancer Research and Treatment, 150(2), 427-437. https://doi.org/10.1007/s10549-015-3331-5
}

Published in:

Breast Cancer Research and Treatment

Document Version:

Peer reviewed version

Queen's University Belfast - Research Portal:

Link to publication record in Queen's University Belfast Research Portal

Publisher rights

Copyright 2015 Springer Science+Business Media

The final publication is available at Springer via http://link.springer.com/article/10.1007\%2Fs10549-015-3331-5

\section{General rights}

Copyright for the publications made accessible via the Queen's University Belfast Research Portal is retained by the author(s) and / or other copyright owners and it is a condition of accessing these publications that users recognise and abide by the legal requirements associated with these rights.

Take down policy

The Research Portal is Queen's institutional repository that provides access to Queen's research output. Every effort has been made to ensure that content in the Research Portal does not infringe any person's rights, or applicable UK laws. If you discover content in the Research Portal that you believe breaches copyright or violates any law, please contact openaccess@qub.ac.uk. 
The association between glucose lowering drug use and mortality among breast cancer patients with type 2 diabetes

Pauline A.J. Vissers, MSc ${ }^{1,2}$, Chris R. Cardwell, $\mathrm{PhD}^{3}$, Lonneke V. van de Poll-Franse, $\mathrm{PhD}^{1,2}$, Ian S. Young, $\mathrm{MD}^{3}$, Frans Pouwer, $\mathrm{PhD}^{1}$, Liam J. Murray, $\mathrm{MD}^{3}$.

${ }^{1}$ CoRPS - Center of Research on Psychology in Somatic diseases, Department of Medical and Clinical Psychology, Tilburg University, The Netherlands

${ }^{2}$ Eindhoven Cancer Registry, Comprehensive Cancer Center The Netherlands, Eindhoven, The Netherlands

${ }^{3}$ Centre for Public Health, Queen's University Belfast, Northern Ireland, United Kingdom

Number of tables and figures: 5

Corresponding author: Pauline Vissers

CoRPS - Center of Research on Psychology in Somatic diseases

Department of Medical and Clinical Psychology, Tilburg University

P.O. Box 90153, 5000 LE Tilburg, The Netherlands

Telephone number: +31 13466 3005, Email address: p.a.j.vissers@tilburguniversity.edu 


\section{Abstract}

Objective: This study assessed the association between glucose lowering drug (GLD) use, including metformin, sulphonylurea derivatives and insulin, after breast cancer diagnosis and breast cancer-specific and all-cause mortality.

Methods: 1,763 breast cancer patients, diagnosed between 1998-2010, with type 2 diabetes were included. Cancer information was retrieved from English cancer registries, prescription data from the UK Clinical Practice Research Datalink and mortality data from the Office of National Statistics (up to January 2012). Time varying Cox regression models were used to calculate HRs and 95\% CIs for the association between GLD use and breast cancer-specific and all-cause mortality.

Results: In 1,057 patients with diabetes before breast cancer, there was some evidence that breast cancerspecific mortality decreased with each year of metformin use (adjusted HR=0.88; 95\%CI 0.75-1.04), with a strong association seen with over 2 years of use (adjusted HR=0.47; 95\%CI:0.26-0.82). Sulphonylurea derivative use for less than 2 years was associated with increased breast cancer-specific mortality (adjusted $\mathrm{HR}=1.70 ; 95 \% \mathrm{CI}: 1.18-2.46$ ) but longer use was not (adjusted HR=0.94; 95\%CI: 0.54-1.66). In 706 patients who developed diabetes after breast cancer, similar patterns were seen for metformin but sulphonylurea derivative use was strongly associated with cancer-specific mortality (adjusted HR: 3.64; 95\%CI:2.16-6.16), with similar estimates for short and long-term users.

Conclusions: This study provides some support for an inverse association between, mainly long-term, metformin use and (breast cancer-specific) mortality. In addition, sulphonylurea derivative use was associated with increased breast cancer-specific mortality, but this should be interpreted cautiously, as it could reflect selective prescribing in advanced cancer patients.

Key words: Glucose lowering drugs, metformin, sulphonylurea derivatives, insulin, diabetes, breast cancer, 


\section{Introduction}

Diabetes occurs in around $16 \%$ of breast cancer patients[1,2] and is associated with a $40 \%$ increased breast cancer-specific[3] and a 50\% increased all-cause mortality[4].

Metformin is currently used as primary treatment for Type 2 diabetes. If metformin monotherapy does not control hyperglycaemia sufficiently, sulphonylurea derivatives (SUs) or insulin may be added or switched to. Recently, metformin, has received much attention for its potential anti-tumour effects. Several laboratory studies show that metformin use is associated with cell growth suppression in breast cancer cells, possibly mediated by activation of 5'-adenosine monophosphate-activated protein kinase (AMPK) [5,6]. Observational studies also show that metformin use is associated with a $20-30 \%$ lower breast cancer incidence[7-9].

Four studies have investigated the association between metformin use and breast cancer-specific mortality or recurrence in breast cancer patients but reported conflicting results[10-13]. A 53\% decreased breast cancerspecific mortality was reported for metformin use versus non-use among human epidermal growth factor receptor 2 positive (HER2+) breast cancer patients[10] whereas the other studies did not find any association[13,11,12]. These studies had several limitations such as small sample size[12,13,10], no investigation of dose-response[12,13,10] and some were restricted to specific breast cancer subtypes (i.e. HER $2+[10]$ or triple negative breast cancer[13]). Additionally, the study that reported a favourable effect for metformin might have been influenced by immortal time bias[14], as metformin users were classified as users from breast cancer diagnosis onwards, and not from the time of actual drug initiation[10]. Only one study used time dependent Cox regression analyses to avoid immortal time bias, but did not include lifestyle related covariates[11]. Conflicting results were also reported among studies that investigated the effect of Glucose Lowering Drugs (GLDs) on all-cause mortality[15,16]. One study reported no effect of metformin use prior or in the three months after breast cancer diagnosis on overall mortality[16], while another study did report a lower overall mortality among metformin users as compared to breast cancer patients without diabetes[15]. However, as these studies did not report on breast cancer-specific deaths, associations in these studies could reflect noncancer deaths[16,15]. Further research is needed to establish the effect of metformin and other GLDs on the prognosis of breast cancer patients with type 2 diabetes.

Therefore, prompted by the promising preclinical evidence, our primary objective was to determine whether breast cancer patients with type 2 diabetes using metformin had reduced breast cancer-specific mortality and all- 
cause mortality. A secondary objective was to investigate the effect of other GLDs on breast cancer-specific and all-cause mortality. 


\section{Methods}

Data sources

This retrospective cohort study used linked data from the Clinical Practice Research Datalink (CPRD), the National Cancer Data Repository (NCDR) and the Office of National Statistics (ONS). The CPRD contains demographical information, clinical diagnoses and prescription data for approximately $7 \%$ of the UK population[17]. The NCDR contains data on all cancer diagnoses in UK cancer registries including data on diagnosis date, site of primary cancer, stage, and treatment. Data regarding deaths were retrieved from the ONS registration which included breast cancer-specific (ICD codes C50.0 to C50.9) and all-cause mortality. The CPRD, NCDR and ONS death data were linked (using an algorithm based upon NHS number, gender, date of birth and postcode) for cancer patients in England. A multicentre research ethics committee gave ethical approval for all observational research using CPRD data.

\section{Study design}

A cohort of female breast cancer patients, diagnosed between 1998 and 2009, with type 2 diabetes was identified. Diabetes diagnosis was defined using previously validated clinical Read codes[18] or the first prescription of a GLD defined below, whichever occurred first. This study includes patients with diabetes prior to breast cancer (prevalent diabetes) as well as patients who developed diabetes after breast cancer diagnosis (incident diabetes). Patients with type 1 diabetes, which was defined as having a type 1 diabetes diagnosis code and a prescription of insulin prior to breast cancer diagnosis for prevalent diabetes patients and within 6 months after diabetes diagnosis for patients with incident diabetes, were excluded. Cancer patients with a previous cancer diagnosis were excluded, apart from in situ neoplasms and non-melanoma skin cancers. The index date was defined as date of breast cancer diagnosis for patients with prevalent diabetes and date of diabetes diagnosis for patients with incident diabetes. Patients were excluded if the index date occurred before they were registered at a CPRD practice, CPRD records at their general practice (GP) were of research quality or if the index date occurred after death or censoring. Patients who received hormone therapy more than 8 weeks prior their breast cancer diagnosis, or with diagnosed polycystic ovary syndrome were excluded. Follow-up started 6 months after the index date to remove deaths that occurred within this period, as it is unlikely that GLD medication use after diagnosis could influence such deaths. In the analysis of incident diabetes patients, the time since breast cancer 
diagnosis remained the underlying time variable, Cox regression models were left-truncated with follow-up beginning 6 months after diabetes diagnosis. The patients were followed till death, the end of registration or last date of data collection of their GP or end of ONS follow up ( $10^{\text {th }}$ of January 2012), whichever occurred first.

\section{Exposure to GLDs}

Exposure to metformin, SUs, other GLDs and insulin were identified using chapter 6.1 of the British National Formulary[19]. Days of exposure were calculated by dividing the prescribed quantity by the number of prescribed tablets/units per day. If the quantity or units per day was missing $(<1 \%$ and $<20 \%$ respectively), the most frequent quantity and the average daily dose per product was used. For insulin the units per day were not reported, so days of exposure was set to 60 days for each prescription. Cumulative days of exposure to all GLDs were calculated in 30 day intervals.

\section{Covariates}

Cancer stage and treatment (surgery, radiotherapy and chemotherapy) within the six months after breast cancer diagnosis were retrieved from the NCDR. Hormone treatment (including tamoxifen and aromatase inhibitor use) in the six months after breast cancer diagnosis was derived from GP prescription records. Smoking and Body Mass Index (BMI) closest to the index date were determined from the GP records; records more than 5 years prior to the index date were ignored. Comorbidities prior to the index date were identified using clinical Read codes which were previously validated with an adapted version of the Charlson comorbidity index[18]. The use of Hormone Replacement Therapy (HRT), low-dose aspirin and statin prior to the index date were retrieved from the GP records. $\mathrm{HbA}_{1 \mathrm{c}}$ measures in \% according to the National Glycohemoglobin Standardization Program (NGSP) were retrieved for the year prior to breast cancer diagnosis for prevalent diabetes patients and between 6 months prior and 6 months after diabetes diagnosis for incident diabetes patients. The $\mathrm{HbA}_{\mathrm{lc}}$ measurement closest to the index date was used in the analyses.

Statistical analyses 
The main analyses used time dependent Cox regression models with time to breast cancer-specific deaths and all-cause mortality as the outcome, where metformin, SU, other GLDs and insulin use were modelled as time varying covariates. A 6 months lag was used, which removes all GLD prescriptions in the 6 months prior to the end of study or death (i.e. as medication use in these months might reflect end of life treatment), as previously recommended[20]. Exposure to GLDs was modelled using time varying ever/never terms (i.e. patients are classified as unexposed until 6 months after first drug prescription and as exposed afterwards). In addition, a linear trend was fitted to assess per year exposure to GLDs, time-varying terms for year of exposure to GLDs, with time varying ever/never terms were included in the model as recommended [21]. Moreover short and longterm exposure was modelled using categories ( $<2$ years of exposure and $\geq 2$ years of exposure). Hazard ratios (HR) and 95\% confidence intervals (95\%CIs) were reported.

An unadjusted model was constructed and included use of metformin, SU, other GLDs and insulin use. The fully adjusted model included the following covariates which were available for the entire cohort: age at breast cancer diagnosis, calendar year of breast cancer diagnosis, diabetes duration for prevalent diabetes patients, breast cancer treatment within 6 months (i.e. dichotomous covariates for surgery, chemotherapy, radiotherapy and hormone therapy), the use of HRT prior to breast cancer diagnosis, and comorbidities prior to the study start (including stroke, chronic pulmonary disease, congestive heart disease, diabetes with complications, myocardial infarction, peptic ulcer disease, peripheral vascular disease and renal disease).

Several sensitivity analyses based on the fully adjusted time varying ever/never analysis were conducted and include additional adjustments for $\mathrm{BMI}$, smoking, stage and $\mathrm{HbA}_{1 \mathrm{c}}$ measures. A sensitivity analysis restricted to patients who had a follow-up $>1$ year in which the lag was increased to 1 year was performed. Among prevalent diabetes patients, a simplified Cox regression analyses was performed comparing GLD use to non-use in the 6 months after diagnosis, removing the need for time varying covariates. Moreover, among prevalent diabetes patients, a nested case cohort analysis was performed. Cases who died of breast cancer were matched on age (5 year intervals) and year of cancer diagnosis ( 2 year intervals) to up to 10 controls within the cohort who lived at least as long after diagnosis as their matched case. The exposure period was defined as the period from breast cancer diagnosis till 6 months prior to death for cases and a period of identical duration from breast cancer diagnosis was defined for the matched controls. Metformin, SU, insulin and other GLD use was determined in the exposure period. Conditional logistic regression was used to calculate odds ratios (OR) and 95\%CIs. All statistical analyses were performed using STATA 13 (College Station, TX). 


\section{Results}

\section{Study population}

1,057 patients with prevalent diabetes at breast cancer diagnosis and 706 patients with incident diabetes were included (Figure 1). The mean age of prevalent diabetes patients was $70.6(\mathrm{SD}=11.3)$ years at breast cancer diagnosis and they were diagnosed with diabetes on average 6.6 $(\mathrm{SD}=6.0)$ years prior (Table 1). During followup, metformin was used by $65 \%$, SUs by $50 \%$, insulin by $21 \%$ and other GLDs by $21 \%$ of the prevalent diabetes patients. 189 (18\%) prevalent diabetes patients used no GLDs, 332 (31\%) used 1 GLD and $536(51 \%)$ used a combination of $\geq 2$ GLDs. The most frequent used combinations were metformin and SUs ( $n=205,19 \%)$, metformin monotherapy $(\mathrm{n}=187,18 \%)$, and metformin, SUs and other GLDs $(\mathrm{n}=105,10 \%)$. Patients who did not use GLDs or who used SUs during follow-up were leaner than other groups e.g. $29 \%$ and $16 \%$ had a BMI $<25 \mathrm{~kg} / \mathrm{m}^{2}$, respectively, compared with $11 \%$ among metformin and insulin users. Insulin users had more complications $(25 \%)$ than other groups and had the highest $\mathrm{HbA}_{1 \mathrm{c}}$ levels (mean=8.2, $\mathrm{SD}=1.8 \% \mathrm{NGSP}$ ). Mean follow-up time from breast cancer diagnosis was 4.4 years $(\mathrm{SD}=2.9$ years, maximum 13.8 years) and a total of 348 prevalent diabetes patients died (150 were breast cancer-specific deaths).

Incident diabetes patients were on average $64.4(\mathrm{SD}=11.4)$ years at breast cancer diagnosis and were diagnosed with diabetes on average $3.3(\mathrm{SD}=2.6)$ years after breast cancer diagnosis (Table 1). Metformin use was similar compared to prevalent diabetes patients (62\% versus $65 \%$ using metformin during follow-up) but SU use, insulin and other GLDs was lower with $30 \%, 5 \%$ and $10 \%$ versus $50 \%, 21 \%$ and $21 \%$, respectively. $224(32 \%)$ incident diabetes patients used no GLDs, 278 (39\%) used 1 GLD and 204 (29\%) used a combination of $\geq 2$ GLDs. The most frequent used combinations were metformin monotherapy $(n=235,33 \%)$, metformin and SUs $(n=115,16 \%)$, and metformin, SUs and other GLDs $(n=37,5 \%)$. Metformin and other GLD users had the highest BMIs with respectively, $47 \%$ and $50 \%$ being obese as compared to $37 \%$ and $29 \%$ for SU and insulin users, respectively. $\mathrm{HbA}_{1 \mathrm{c}}$ levels were highest among insulin users with an average of $8.2 \%$ NGSP. Mean follow-up from diabetes diagnosis was 3.9 years ( $\mathrm{SD}=2.7$ years, and maximum 13.0 years) and a total of 134 patients died (68 were breast cancer-specific deaths).

The association between GLD use and mortality

Breast cancer patients with prevalent diabetes 
Breast cancer-specific mortality rates were lower in metformin users compared with non-users $(\mathrm{HR}=0.64$; 95\% CI:0.46-0.91), although this was attenuated after adjustment for potential confounders (adjusted HR=0.78; 95\%CI:0.55-1.12) (Table 2). The majority of this attenuation could be explained by adjustment for age and year of breast cancer diagnosis (HR adjusted for age and year of diagnosis=0.79; 95\%CI:0.55-1.12). Sensitivity analyses showed that adjustment for stage further attenuated the effect of metformin $(\mathrm{HR}=0.96$; $95 \% \mathrm{CI}: 0.53$ 1.75) while increasing the lag to 1 year and the case control analysis showed similar results (Table 4). The association was not observed per year of metformin use (unadjusted HR=0.88; 95\%CI:0.75-1.04, adjusted $\mathrm{HR}=0.88 ; 95 \% \mathrm{CI}: 0.75-1.04)$ (Table 2). A more marked association with breast cancer-specific mortality was observed among individuals using metformin for $\geq 2$ years (adjusted $\mathrm{HR}=0.47 ; 95 \% \mathrm{CI}: 0.26-0.82$ ), rather than for shorter periods (adjusted $\mathrm{HR}=0.88 ; 95 \% \mathrm{CI}: 0.61-1.27$ ). In sensitivity analyses the association between metformin use for $\geq 2$ years was attenuated slightly after adjustment for BMI (HR=0.53; 95\%CI:0.28-1.00), or after increasing the lag to 1 year $(\mathrm{HR}=0.54 ; 95 \% \mathrm{CI}: 0.30-1.00)$. Adjustment for stage at diagnosis (available for 39 percent of cases) further attenuated this association $(\mathrm{HR}=0.62 ; 95 \% \mathrm{CI}: 0.25-1.55)$ (data not shown).

Breast cancer-specific mortality was increased in SU users compared with non-users $(\mathrm{HR}=1.56 ; 95 \% \mathrm{CI}=1.11$ 2.19), but attenuated after adjustments $(\mathrm{HR}=1.41 ; 95 \% \mathrm{CI}=1.00-1.99)$. As before, the majority of this attenuation could be explained by adjustment for age and year of breast cancer diagnosis (HR adjusted for age and year of diagnosis $=1.37 ; 95 \% \mathrm{CI}: 0.97-1.93)$. Sensitivity analysis showed that adjustments for BMI and smoking further attenuated the association; $\mathrm{HR}=1.36 ; 95 \% \mathrm{CI}: 0.94-1.99$ and $\mathrm{HR}=1.27 ; 95 \% \mathrm{CI}: 0.86-1.89$ respectively (data not shown). Additional adjustments for stage resulted in a slightly higher hazard ratio for SU use (HR =1.76; 95\% CI:0.99-1.34), but the case control analysis showed similar results (Table 4). No significant association was seen per year increase in sulphonlyurea derivative use (unadjusted HR=0.96; 95\%CI:0.81-1.14 and adjusted $\mathrm{HR}=0.96$; 95\%CI:0.81-1.15, Table 2). Further analysis revealed that SU use for $<2$ years was associated with an increase in breast cancer-specific mortality ( $\mathrm{HR}=1.70 ; 95 \% \mathrm{CI}: 1.18-2.46)$ whereas longer use ( $\geq 2$ years) was not $(\mathrm{HR}=0.94 ; 95 \% \mathrm{CI}: 0.54-1.66)$. A similar pattern was seen for insulin users, although based on smaller numbers. There was little evidence of an association between use of other GLDs and breast cancer-specific mortality.

\section{Breast cancer patients with incident diabetes}

No association between breast cancer-specific mortality and metformin use was seen among breast cancer patients with incident diabetes (unadjusted $\mathrm{HR}=0.97 ; 95 \% \mathrm{CI}: 0.58-1.71$, adjusted $\mathrm{HR}=0.99 ; 95 \% \mathrm{CI}=0.58-1.71$ ). 
However, cumulative exposure to metformin was associated with breast-cancer specific mortality $(\mathrm{HR}=0.73$; 95\%CI:0.56-0.95), and this effect remained after adjustments (HR=0.73; 95\%CI:0.56-0.96). Although not significant, similar patterns to those with prevalent diabetes were observed for $\geq 2$ years metformin use (Table 3).

Ever versus never use of SUs was associated with substantially higher breast cancer-specific mortality (unadjusted $\mathrm{HR}=3.41 ; 95 \% \mathrm{CI}: 2.07-5.64$ and adjusted $\mathrm{HR}=3.15 ; 95 \% \mathrm{CI}: 1.87-5.30$ ). Additional adjustment for stage and the use of a 1 year lag slightly attenuated the association but this effect remained significant (Table 4). No association between breast cancer-specific mortality and cumulative SU exposure per year was observed (adjusted HR=0.88; 95\%CI:0.66-1.16) (Table 3). Both $<2$ years and $\geq 2$ years SU use was associated with higher breast cancer-specific mortality; $\mathrm{HR}=3.51(95 \% \mathrm{CI}: 2.04-6.06)$ and $\mathrm{HR}=3.51$ (95\%CI:1.31-9.36), respectively. The low number of incident diabetes patients using insulin or other GLDs hampered the calculation of reliable estimates of mortality risk.

For both prevalent and incident diabetes patients, additional adjustments for statin and aspirin use prior to breast cancer diagnosis did not materially affect observed associations between GLD use and breast cancer-specific mortality (data not shown). Analysis of all-cause mortality, also shown in Table 2 and 3, displayed similar patterns to the breast cancer-specific analyses. 


\section{Discussion}

This study showed some evidence of lower breast cancer-specific and all-cause mortality rates in breast cancer patients with diabetes who were treated with metformin, especially among longer term users ( $\geq 2$ years exposure), but these associations were attenuated in sensitivity analyses. In contrast, SU use was associated with substantially increased breast cancer-specific and all-cause mortality, however there was no dose response association, these associations were most marked in short-term users, and in patients who developed diabetes after their breast cancer diagnosis.

Only one previous study[11] has provided data relating to the potential effects of metformin, SUs, insulin and other GLDs on breast cancer-specific mortality, and adjusted for the use of other GLDs. This study, revealed no significant association between metformin use and mortality[11]. However, we observed some evidence of an association for long-term use of metformin on mortality. Also, Lega et al. did not find an association between SU use versus non-use and breast cancer-specific (HR=0.97; 95\%CI:0.86-1.16) or all-cause mortality $(\mathrm{HR}=0.98 ; 95 \% \mathrm{CI}: 0.94-1.04)$, nor for SU use modelled per year of exposure[11]. In contrast, we observed an increased breast cancer-specific and all-cause mortality for short-term SU use among those with prevalent diabetes at breast cancer diagnosis. Among those with incident diabetes we found a more pronounced increased mortality among SU users in all analyses. Lega et al did not assess short and long-term SU use and they did not include patients who developed diabetes after their breast cancer diagnosis[11].

The observed reduction in cancer-specific mortality in longer-term metformin users is consistent with findings from preclinical studies suggesting that metformin may have anti-tumour properties. Metformin may directly supress breast cancer cell growth via activation of the AMP-activated protein kinase, resulting in downstream signalling of the protein kinase, MTOR, which regulates cell growth[22,23]. Moreover, due to the activation of the AMP-activated protein kinase and inhibition of MTOR, metformin might act synergistically with chemotherapeutic agents[24], and positively influence response to adjuvant chemotherapy in diabetic breast cancer patients[25]. Metformin may also work through an indirect mechanism by improving insulin sensitivity, thereby reducing insulin levels[26], and decreasing activation of IGF-1 receptors [27]. Deactivation of IGF-1 may inhibit Cyr61, and thereby suppress breast cancer growth and invasion[28]. On the other hand, the observed reduction in breast cancer-specific mortality rates in metformin users could also be due to residual confounding or reflect chance, particularly as the association was most apparent among long-term users of metformin. 
Further evidence will be provided by an ongoing randomised controlled trial of metformin versus placebo in over 3,500 women with breast cancer, although results will not be reported until the end of 2016[29,30].

Previous studies reported increased mortality rates in cancer patients using SUs but of less magnitude than associations seen in our study[31,16]. We believe that the increased cancer-specific mortality in SU users apparent in our data should be interpreted cautiously for various reasons. First, we did not have a prior hypothesis regarding the association between SUs and mortality. Second, the association with SUs did not follow a dose response, which is counterintuitive. Third, although strong associations were seen in those with incident diabetes the risk estimates were based on small numbers of deaths. Fourth, a proportion of the diabetes occurring after a breast cancer diagnosis might partly be due to treatment for advanced/recurrent disease (e.g. steroids), which is often a transient condition. Finally, in patients with advanced cancer it has been recommended that SUs are used in preference to metformin due to the gastro-intestinal side effects of metformin[32], consequently these drugs may be spuriously associated with increased cancer-specific mortality.

From a physiological point of view, it is possible that SUs detrimentally affect breast cancer progression/metastasis, possibly mediated through hyperinsulinemia, as SUs increase insulin secretion[33] and preclinical studies have shown that hyperinsulinemia may promote breast cancer metastasis to the lung[34]. Moreover, observational studies have shown that hyperinsulinemia is associated with increased cancer-specific mortality[35]. Despite the caveats mentioned above, the associations we have seen between SU use and mortality in breast cancer patients are worthy of further investigation.

This study used data from a large population-based database which is of validated high quality[17,18]. Importantly, time dependent analyses were performed to avoid immortal time bias[14], we accounted for cumulative exposure to GLDs, and conducted sensitivity analyses to investigate the robustness of our findings. In addition, GLDs are not available 'over the counter' in the UK, so it is likely that we captured all GLD use in our study, apart perhaps from use during care within hospital or a hospice. However, this study also has several limitations. We do not have data on patients' compliance with prescribed medications. Cancer stage at diagnosis was missing in $60 \%$ of our study population, although stage distribution appeared similar in metformin users and non-users. Additional adjustments for stage attenuated observed hazard ratios but this appeared to result from the restriction of the dataset to those with available stage, rather than an effect of adjustment for stage per se. We did not have data on disease progression while GLD use may have changed following cancer recurrence, 
although associated biases should be reduced in lagged analyses. Moreover, there may have been some misclassification regarding the cause of death.

In conclusion, this study provides some support for an inverse association between metformin exposure and (breast cancer-specific) mortality among breast cancer patients. In addition, an increased breast cancer-specific mortality was observed among SU users. This finding should be interpreted cautiously, as it could reflect selective prescribing in advanced cancer patients, but merits further investigation. 
Acknowledgements: This study is based partly on data from the Clinical Practice Research Datalink, obtained under license from the United Kingdom Medicines and Healthcare products Regulatory Agency. However, the interpretation and conclusions contained in this study are those of the authors alone.

Conflict of interest: The authors declare no conflict of interest relevant to this article.

Funding: C.R.C was supported by a United Kingdom National Institute for Health Research awarded Career Development Fellowship funded by the Health and Social Care Research and Development (Public Health Agency, Northern Ireland), which also funded access to the Clinical Practice Research Database dataset. The funders had no role in the study design; collection, analysis and interpretation of the data; writing of the report; or the decision to submit for publication. 


\section{References}

1. Wolf I, Sadetzki S, Catane R, Karasik A, Kaufman B (2005) Diabetes mellitus and breast cancer. Lancet Oncol 6 (2):103-111. doi:10.1016/s1470-2045(05)01736-5

2. van de Poll-Franse LV, Houterman S, Janssen-Heijnen ML, Dercksen MW, Coebergh JW, Haak HR (2007) Less aggressive treatment and worse overall survival in cancer patients with diabetes: a large population based analysis. Int J Cancer 120 (9):1986-1992. doi:10.1002/ijc.22532

3. De Bruijn KM, Arends LR, Hansen BE, Leeflang S, Ruiter R, van Eijck CH (2013) Systematic review and meta-analysis of the association between diabetes mellitus and incidence and mortality in breast and colorectal cancer. Br J Surg 100 (11):1421-1429. doi:10.1002/bjs.9229

4. Peairs KS, Barone BB, Snyder CF, Yeh HC, Stein KB, Derr RL, Brancati FL, Wolff AC (2011) Diabetes mellitus and breast cancer outcomes: a systematic review and meta-analysis. J Clin Oncol 29 (1):40-46. doi:10.1200/jco.2009.27.3011

5. Du Y, Zheng H, Wang J, Ren Y, Li M, Gong C, Xu F, Yang C (2014) Metformin inhibits histone H2B monoubiquitination and downstream gene transcription in human breast cancer cells. Oncol Lett 8 (2):809-812. doi:10.3892/ol.2014.2158

6. Queiroz EA, Puukila S, Eichler R, Sampaio SC, Forsyth HL, Lees SJ, Barbosa AM, Dekker RF, Fortes ZB, Khaper N (2014) Metformin induces apoptosis and cell cycle arrest mediated by oxidative stress, AMPK and FOXO3a in MCF-7 breast cancer cells. PLoS One 9 (5):e98207. doi:10.1371/journal.pone.0098207

7. Col NF, Ochs L, Springmann V, Aragaki AK, Chlebowski RT (2012) Metformin and breast cancer risk: a meta-analysis and critical literature review. Breast Cancer Res Treat 135 (3):639-646. doi:10.1007/s10549-0122170-x

8. Bosco JL, Antonsen S, Sorensen HT, Pedersen L, Lash TL (2011) Metformin and incident breast cancer among diabetic women: a population-based case-control study in Denmark. Cancer Epidemiol Biomarkers Prev 20 (1):101-111. doi:10.1158/1055-9965.epi-10-0817

9. Chlebowski RT, McTiernan A, Wactawski-Wende J, Manson JE, Aragaki AK, Rohan T, Ipp E, Kaklamani VG, Vitolins M, Wallace R, Gunter M, Phillips LS, Strickler H, Margolis K, Euhus DM (2012) Diabetes, metformin, and breast cancer in postmenopausal women. J Clin Oncol 30 (23):2844-2852.

doi:10.1200/jco.2011.39.7505

10. He X, Esteva FJ, Ensor J, Hortobagyi GN, Lee MH, Yeung SC (2012) Metformin and thiazolidinediones are associated with improved breast cancer-specific survival of diabetic women with HER2+ breast cancer. Ann Oncol 23 (7):1771-1780. doi:10.1093/annonc/mdr534

11. Lega IC, Austin PC, Gruneir A, Goodwin PJ, Rochon PA, Lipscombe LL (2013) Association between metformin therapy and mortality after breast cancer: a population-based study. Diabetes Care 36 (10):30183026. doi: $10.2337 / \mathrm{dc} 12-2535$

12. Oppong BA, Pharmer LA, Oskar S, Eaton A, Stempel M, Patil S, King TA (2014) The effect of metformin on breast cancer outcomes in patients with type 2 diabetes. Cancer Med. doi:10.1002/cam4.259

13. Bayraktar S, Hernadez-Aya LF, Lei X, Meric-Bernstam F, Litton JK, Hsu L, Hortobagyi GN, GonzalezAngulo AM (2012) Effect of metformin on survival outcomes in diabetic patients with triple receptor-negative breast cancer. Cancer 118 (5):1202-1211. doi:10.1002/cncr.26439

14. Suissa S, Azoulay L (2012) Metformin and the risk of cancer: time-related biases in observational studies. Diabetes Care 35 (12):2665-2673. doi:10.2337/dc12-0788

15. Hou G, Zhang S, Zhang X, Wang P, Hao X, Zhang J (2013) Clinical pathological characteristics and prognostic analysis of 1,013 breast cancer patients with diabetes. Breast Cancer Res Treat 137 (3):807-816. doi:10.1007/s10549-012-2404-y

16. Currie CJ, Poole CD, Jenkins-Jones S, Gale EA, Johnson JA, Morgan CL (2012) Mortality after incident cancer in people with and without type 2 diabetes: impact of metformin on survival. Diabetes Care 35 (2):299304. doi:10.2337/dc11-1313

17. Jick H, Jick SS, Derby LE (1991) Validation of information recorded on general practitioner based computerised data resource in the United Kingdom. BMJ 302 (6779):766-768. doi:10.1136/bmj.302.6779.766 18. Khan NF, Perera R, Harper S, Rose PW (2010) Adaptation and validation of the Charlson Index for Read/OXMIS coded databases. BMC Fam Pract 11:1. doi:10.1186/1471-2296-11-1

19. British Medical Association and the Royal Pharmaceutical Society of Great Britain (2013) British National Formulary, http://www.bnf.org/bnf/index.htm.

20. Chubak J, Boudreau DM, Wirtz HS, McKnight B, Weiss NS (2013) Threats to validity of nonrandomized studies of postdiagnosis exposures on cancer recurrence and survival. J Natl Cancer Inst 105 (19):1456-1462. doi:10.1093/jnci/djt211

21. Kirkwood BR, Sterne JAC (2003) Essential Medical Statistics. Second edn. Blackwell publishing, 22. Dowling RJ, Zakikhani M, Fantus IG, Pollak M, Sonenberg N (2007) Metformin inhibits mammalian target of rapamycin-dependent translation initiation in breast cancer cells. Cancer Res 67 (22):10804-10812. doi:10.1158/0008-5472.can-07-2310 
23. Zakikhani M, Dowling R, Fantus IG, Sonenberg N, Pollak M (2006) Metformin is an AMP kinasedependent growth inhibitor for breast cancer cells. Cancer Res 66 (21):10269-10273. doi:10.1158/00085472.can-06-1500

24. Rocha GZ, Dias MM, Ropelle ER, Osório-Costa F, Rossato FA, Vercesi AE, Saad MJA, Carvalheira JBC (2011) Metformin Amplifies Chemotherapy-Induced AMPK Activation and Antitumoral Growth. Clin Cancer Res 17 (12):3993-4005. doi:10.1158/1078-0432.ccr-10-2243

25. Jiralerspong S, Palla SL, Giordano SH, Meric-Bernstam F, Liedtke C, Barnett CM, Hsu L, Hung MC, Hortobagyi GN, Gonzalez-Angulo AM (2009) Metformin and pathologic complete responses to neoadjuvant chemotherapy in diabetic patients with breast cancer. J Clin Oncol 27 (20):3297-3302.

doi:10.1200/jco.2009.19.6410

26. Viollet B, Guigas B, Sanz Garcia N, Leclerc J, Foretz M, Andreelli F (2012) Cellular and molecular mechanisms of metformin: an overview. Clin Sci (Lond) 122 (6):253-270. doi:10.1042/cs20110386

27. Duggan C, Wang CY, Neuhouser ML, Xiao L, Smith AW, Reding KW, Baumgartner RN, Baumgartner KB, Bernstein L, Ballard-Barbash R, McTiernan A (2013) Associations of insulin-like growth factor and insulin-like growth factor binding protein-3 with mortality in women with breast cancer. Int J Cancer 132 (5):1191-1200. doi:10.1002/ijc. 27753

28. Sarkissyan S, Sarkissyan M, Wu Y, Cardenas J, Koeffler HP, Vadgama JV (2014) IGF-1 regulates Cyr61 induced breast cancer cell proliferation and invasion. PLoS One 9 (7):e103534.

doi:10.1371/journal.pone.0103534

29. Goodwin P, Stambolic V, Lemieux J, Chen B, Parulekar W, Gelmon K, Hershman D, Hobday T, Ligibel J, Mayer I, Pritchard K, Whelan T, Rastogi P, Shepherd L (2011) Evaluation of metformin in early breast cancer: a modification of the traditional paradigm for clinical testing of anti-cancer agents. Breast Cancer Res Treat 126 (1):215-220. doi:10.1007/s10549-010-1224-1

30. NCIC Clinical Trials Group, National Cancer Institute A Phase III Randomized Trial of Metformin vs Placebo in Early Stage Breast Cancer. In: ClinicalTrials.gov [Internet]. Available from: https://clinicaltrials.gov/ct2/show/NCT01101438. NLM Identifier: NCT01101438.

31. Bowker SL, Majumdar SR, Veugelers P, Johnson JA (2006) Increased cancer-related mortality for patients with type 2 diabetes who use sulfonylureas or insulin. Diabetes Care 29 (2):254-258

32. McCoubrie R, Jeffrey D, Paton C, Dawes L (2005) Managing diabetes mellitus in patients with advanced cancer: a case note audit and guidelines. European Journal of Cancer Care 14 (3):244-248. doi:10.1111/j.13652354.2005.00564.x

33. Rendell M (2004) The role of sulphonylureas in the management of type 2 diabetes mellitus. Drugs 64 (12):1339-1358

34. Ferguson RD, Novosyadlyy R, Fierz Y, Alikhani N, Sun H, Yakar S, Leroith D (2012) Hyperinsulinemia enhances c-Myc-mediated mammary tumor development and advances metastatic progression to the lung in a mouse model of type 2 diabetes. Breast Cancer Res 14 (1):R8. doi:10.1186/bcr3089

35. Perseghin G, Calori G, Lattuada G, Ragogna F, Dugnani E, Garancini MP, Crosignani P, Villa M, Bosi E, Ruotolo G, Piemonti L (2012) Insulin resistance/hyperinsulinemia and cancer mortality: the Cremona study at the 15th year of follow-up. Acta Diabetol 49 (6):421-428. doi:10.1007/s00592-011-0361-2 
Figure 1 Patient selection

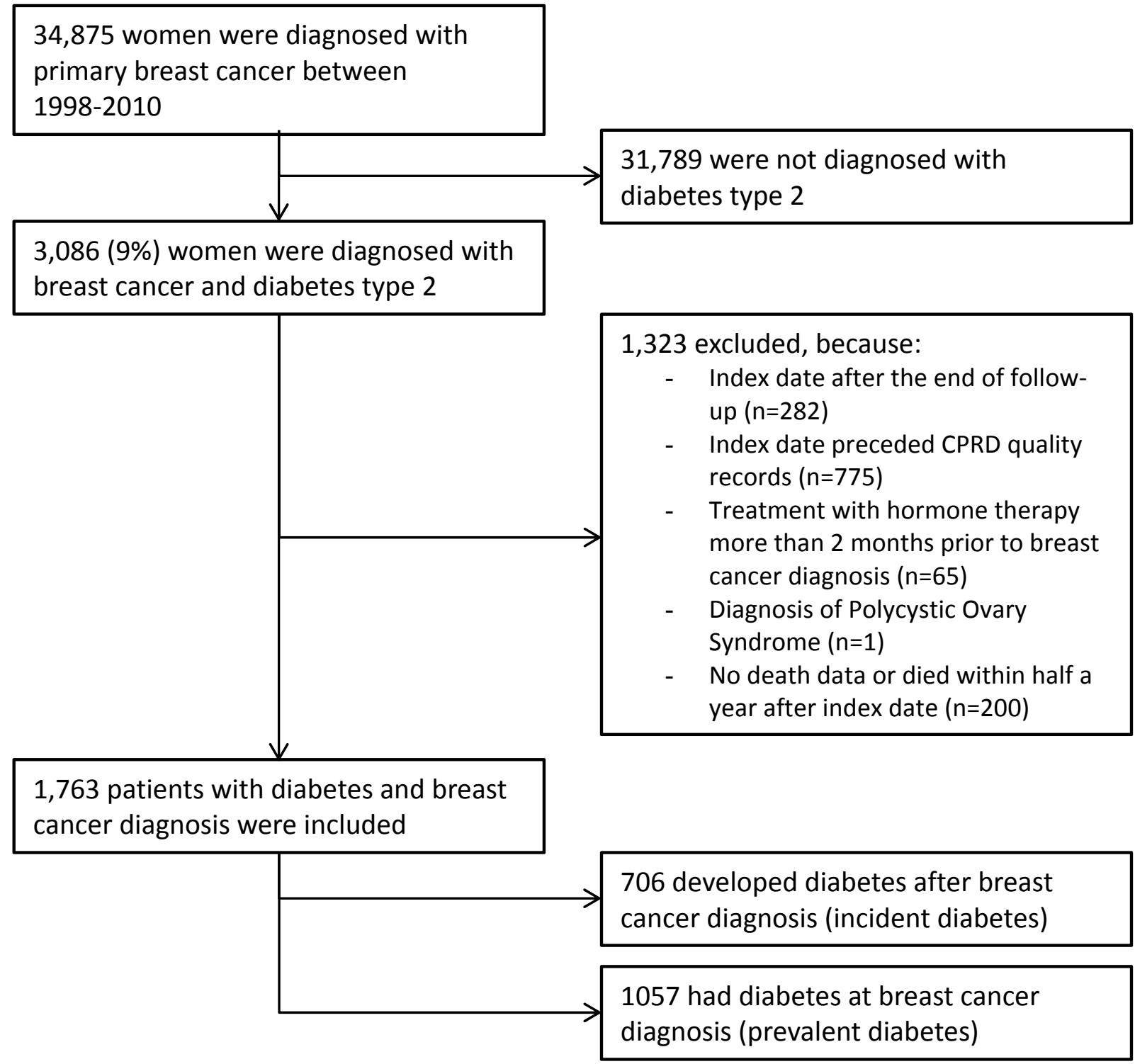


Table 1 Descriptives of the study population including patients with prevalent diabetes at breast cancer diagnosis and incident diabetes after breast cancer diagnosis

\begin{tabular}{|c|c|c|c|c|c|c|c|c|c|c|c|c|}
\hline & \multicolumn{6}{|c|}{ Prevalent diabetes $(n=1,057)$} & \multicolumn{6}{|c|}{ Incident diabetes $(n=706)$} \\
\hline & Total & Metformin & SU & Insulin & Other GLDs & $\begin{array}{l}\text { No GLD } \\
\text { use }\end{array}$ & Total & Metformin & SU & Insulin & Other GLDs & $\begin{array}{l}\text { No GLD } \\
\text { use }\end{array}$ \\
\hline $\mathrm{N}(\%)$ & $1057(100)$ & $688(65)$ & $528(50)$ & $220(21)$ & $220(21)$ & $189(18)$ & $706(100)$ & $437(62)$ & $210(30)$ & $35(5)$ & $74(10)$ & $224(32)$ \\
\hline Age at $\mathrm{BC}$ diagnosis (yrs) ${ }^{\mathrm{a}}$ & $70.6(11.3)$ & $68.6(11.0)$ & $70.6(11.2)$ & $66.9(10.6)$ & $66.2(10.5)$ & $74.4(11.1)$ & $64.4(11.4)$ & $62.1(10.7)$ & $64.6(10.8)$ & $61.6(11.4)$ & $60.9(8.8)$ & $67.7(11.4)$ \\
\hline \multicolumn{13}{|l|}{$\mathrm{BMI}\left(\mathrm{kg} / \mathrm{m}^{2}\right)$} \\
\hline$<25 \mathrm{~kg} / \mathrm{m}^{2}$ & $172(16)$ & $77(11)$ & $85(16)$ & $25(11)$ & $18(8)$ & $54(29)$ & $55(8)$ & $26(6)$ & $14(7)$ & $4(11)$ & $3(4)$ & $26(12)$ \\
\hline $25-30 \mathrm{~kg} / \mathrm{m}^{2}$ & $325(31)$ & $219(32)$ & $175(33)$ & $66(30)$ & $63(29)$ & $52(28)$ & $164(23)$ & 84 (19) & $41(20)$ & $8(23)$ & $14(19)$ & $67(30)$ \\
\hline$\geq 30 \mathrm{~kg} / \mathrm{m}^{2}$ & $456(43)$ & $338(49)$ & $216(41)$ & $111(50)$ & $124(56)$ & $62(33)$ & $280(40)$ & $204(47)$ & $78(37)$ & $10(29)$ & $37(50)$ & $66(29)$ \\
\hline Missing & $104(10)$ & $54(8)$ & $52(10)$ & $18(8)$ & $15(7)$ & $21(11)$ & $207(30)$ & $123(28)$ & $77(37)$ & $13(37)$ & $20(27)$ & $65(29)$ \\
\hline \multicolumn{13}{|l|}{ Smoking status } \\
\hline Never & $570(54)$ & $373(54)$ & $289(55)$ & $119(54)$ & $118(54)$ & $103(55)$ & 345 (49) & $200(46)$ & $90(43)$ & $14(40)$ & $29(39)$ & $126(56)$ \\
\hline Ever & $368(35)$ & $247(36)$ & $169(32)$ & $78(35)$ & $79(36)$ & $66(35)$ & $250(35)$ & $164(38)$ & $76(36)$ & $16(46)$ & $31(42)$ & $71(32)$ \\
\hline Missing & $119(11)$ & $68(10)$ & $70(13)$ & $23(10)$ & $23(10)$ & $20(11)$ & $111(16)$ & $73(17)$ & $44(21)$ & $5(14)$ & $14(19)$ & $27(12)$ \\
\hline \multicolumn{13}{|l|}{ Comorbidities } \\
\hline Diabetes with complications & $131(12)$ & $82(12)$ & $63(12)$ & $56(25)$ & $28(13)$ & $13(7)$ & $0(0)$ & $0(0)$ & $0(0)$ & $0(0)$ & $0(0)$ & $0(0)$ \\
\hline Stroke & $109(10)$ & $61(9)$ & $58(11)$ & $25(11)$ & $20(9)$ & $21(11)$ & $40(6)$ & $16(4)$ & $9(4)$ & $2(6)$ & $1(1)$ & $21(9)$ \\
\hline Chronic pulmonary disease & $209(20)$ & $138(20)$ & $102(19)$ & $36(16)$ & $52(24)$ & $37(20)$ & $139(20)$ & $89(20)$ & $41(20)$ & $8(23)$ & $18(24)$ & $41(18)$ \\
\hline Heart disease & $163(15)$ & $82(12)$ & $75(14)$ & $41(19)$ & $23(10)$ & $33(17)$ & $64(9)$ & $34(8)$ & $21(10)$ & $2(6)$ & $5(7)$ & $23(10)$ \\
\hline $\begin{array}{l}\text { Time between diabetes and breast } \\
\text { cancer diagnosis (yrs) }{ }^{\text {a }}\end{array}$ & $6.6(6.0)$ & $6.4(5.4)$ & $6.9(5.8)$ & $10.0(6.9)$ & $6.7(5.0)$ & $5.1(6.0)$ & - & - & - & - & - & - \\
\hline $\begin{array}{l}\text { Time between breast cancer and } \\
\text { diabetes diagnosis }(\mathrm{yrs})^{\mathrm{a}}\end{array}$ & - & - & - & - & - & - & $3.3(2.6)$ & $3.1(2.5)$ & $2.7(2.4)$ & $2.4(2.1)$ & $2.6(1.9)$ & $3.9(2.9)$ \\
\hline $\mathrm{HbA}_{1 \mathrm{c}}(\% \mathrm{NGSP})^{\mathrm{a}}$ & $7.2(1.4)$ & $7.4(1.4)$ & $7.5(1.5)$ & $8.2(1.8)$ & $7.6(1.4)$ & $6.1(0.7)$ & $7.2(1.4)$ & $7.5(1.6)$ & $7.9(1.7)$ & $8.2(2.3)$ & $7.9(1.7)$ & $6.5(4.9)$ \\
\hline \multicolumn{13}{|l|}{ GLD use after BC diagnosis } \\
\hline Metformin & $688(65)$ & $688(100)$ & $397(75)$ & $157(71)$ & $193(88)$ & - & $437(62)$ & $437(100)$ & $172(82)$ & $28(80)$ & $72(97)$ & - \\
\hline Sulphonylurea derivatives & $528(50)$ & $397(58)$ & $528(100)$ & $101(46)$ & $167(76)$ & - & $210(30)$ & $172(39)$ & $210(100)$ & $22(63)$ & $47(64)$ & - \\
\hline Insulin & $220(21)$ & $157(23)$ & $101(19)$ & $220(100)$ & $60(28)$ & - & $35(5)$ & $28(6)$ & $22(10)$ & $35(100)$ & $13(18)$ & - \\
\hline Other GLDs & $220(21)$ & $193(28)$ & $167(32)$ & $60(27)$ & $220(100)$ & - & $74(10)$ & 72 (16) & $47(22)$ & $13(37)$ & $74(100)$ & - \\
\hline No GLDs & $189(18)$ & - & - & - & - & $189(100)$ & $224(32)$ & - & - & - & - & $224(100)$ \\
\hline \multicolumn{13}{|l|}{ Cancer stage } \\
\hline I & $167(16)$ & 109 (16) & $81(15)$ & 41 (19) & $40(18)$ & $32(17)$ & $140(20)$ & $89(20)$ & $30(14)$ & $2(6)$ & $10(14)$ & $46(21)$ \\
\hline II & $186(18)$ & $131(19)$ & $100(19)$ & 42 (19) & $44(20)$ & $27(14)$ & $175(25)$ & $120(27)$ & $61(29)$ & $15(43)$ & $20(27)$ & $41(18)$ \\
\hline III & $43(4)$ & $26(4)$ & $22(4)$ & $8(4)$ & $8(4)$ & $9(5)$ & $24(3)$ & $10(2)$ & $6(3)$ & $3(9)$ & $2(3)$ & $12(5)$ \\
\hline IV & $14(1)$ & $6(1)$ & $4(1)$ & $2(1)$ & $1(0)$ & $5(3)$ & $9(1)$ & $4(1)$ & $6(3)$ & $0(0)$ & $0(0)$ & $2(1)$ \\
\hline Missing & $647(61)$ & $416(60)$ & $321(61)$ & $127(58)$ & $127(58)$ & $116(61)$ & $358(51)$ & $214(49)$ & $107(51)$ & $15(43)$ & $42(57)$ & $123(55)$ \\
\hline \multicolumn{13}{|l|}{$\begin{array}{l}\text { Cancer treatment in } 6 \text { months } \\
\text { after } \mathrm{BC} \text { diagnosis }\end{array}$} \\
\hline Surgery & $817(77)$ & $561(82)$ & $413(78)$ & $172(78)$ & $188(85)$ & $139(74)$ & $626(89)$ & $399(91)$ & $190(90)$ & $34(97)$ & $70(95)$ & $190(85)$ \\
\hline Chemotherapy & $152(14)$ & $118(17)$ & $76(14)$ & $39(18)$ & $42(19)$ & $14(7)$ & $163(23)$ & $119(27)$ & $64(30)$ & $15(43)$ & $21(28)$ & $32(14)$ \\
\hline Radiotherapy & $419(40)$ & $305(44)$ & $209(40)$ & $97(44)$ & $104(47)$ & $58(31)$ & $337(48)$ & $225(51)$ & $103(49)$ & $14(40)$ & $40(54)$ & $97(43)$ \\
\hline Hormone treatment & $821(78)$ & $520(76)$ & $415(79)$ & $166(75)$ & $156(71)$ & $155(82)$ & $516(73)$ & $302(69)$ & $153(73)$ & $23(67)$ & $50(68)$ & $175(78)$ \\
\hline HRT before $\mathrm{BC}$ diagnosis & $284(27)$ & $205(30)$ & $136(26)$ & $84(38)$ & $80(36)$ & $43(23)$ & $240(34)$ & $153(35)$ & $61(29)$ & $17(49)$ & $30(41)$ & $75(33)$ \\
\hline
\end{tabular}

${ }^{\mathrm{a}}$ Values reported are means and sd. 
Table 2 The association between GLD use and breast cancer-specific and all-cause mortality among breast cancer patients with prevalent diabetes.

\begin{tabular}{|c|c|c|c|c|c|c|c|c|c|}
\hline & \multirow{3}{*}{$\begin{array}{l}\text { Nos. of } \\
\text { BC /all } \\
\text { deaths }\end{array}$} & \multirow{3}{*}{$\begin{array}{c}\text { Nos. } \\
\text { of } \\
\text { patients }\end{array}$} & \multirow{3}{*}{$\begin{array}{l}\text { Person } \\
\text { years }\end{array}$} & \multicolumn{2}{|c|}{ Unadjusted analyses } & \multicolumn{4}{|c|}{ Adjusted analyses } \\
\hline & & & & Ever vs. never ${ }^{a}$ & Per year of use ${ }^{b}$ & Ever vs. never ${ }^{a, c}$ & Per year of use ${ }^{b, c}$ & $\begin{array}{l}<2 \text { years use } \\
\text { versus none }^{c}\end{array}$ & $\begin{array}{c}>2 \text { years use versus } \\
\text { none }^{c}\end{array}$ \\
\hline & & & & $\operatorname{HR}(95 \% \mathrm{CI})$ & $\operatorname{HR}(95 \% \mathrm{CI})$ & $\mathrm{HR}(95 \% \mathrm{CI})$ & $\mathrm{HR}(95 \% \mathrm{CI})$ & HR $(95 \% \mathrm{CI})$ & HR $(95 \% \mathrm{CI})$ \\
\hline \multicolumn{10}{|c|}{ Breast cancer-specific mortality } \\
\hline Metformin & & & & & & & & & \\
\hline Yes & 77 & 688 & 2,512 & $0.64(0.46-0.91)^{*}$ & $0.88(0.75-1.04)$ & $0.78(0.55-1.12)$ & $0.88(0.75-1.04)$ & $0.88(0.61-1.27)$ & $0.47(0.26-0.82)^{*}$ \\
\hline No & 73 & 369 & 1,612 & & & & & & \\
\hline \multicolumn{10}{|l|}{ SU } \\
\hline Yes & 78 & 528 & 1,839 & $1.56(1.11-2.19)^{*}$ & $0.96(0.81-1.14)$ & $1.41(1.00-1.99)$ & $0.96(0.81-1.15)$ & $1.70(1.18-2.46)^{*}$ & $0.94(0.54-1.66)$ \\
\hline \multicolumn{8}{|l|}{ Insulin } & & \\
\hline Yes & 29 & 220 & 733 & $1.25(0.82-1.89)$ & $1.03(0.84-1.26)$ & $1.37(0.87-2.14)$ & $1.04(0.85-1.28)$ & $1.63(0.99-2.68)$ & $1.05(0.51-2.18)$ \\
\hline No & 121 & 837 & 3,391 & & & & & & \\
\hline \multicolumn{10}{|l|}{ Other GLDs } \\
\hline Yes & 25 & 220 & 705 & $1.00(0.63-1.57)$ & $0.96(0.73-1.25)$ & $1.12(0.70-1.78)$ & $0.92(0.70-1.21)$ & $1.26(0.76-2.08)$ & $1.10(0.48-2.52)$ \\
\hline No & 125 & 837 & 3,419 & & & & & & \\
\hline \multicolumn{10}{|c|}{ All-cause mortality } \\
\hline Metformin & & & & & & & & & \\
\hline Yes & 174 & 688 & 2,512 & $0.62(0.50-0.78)^{*}$ & $0.91(0.82-1.01)$ & $0.85(0.67-1.07)$ & $0.93(0.84-1.03)$ & $0.90(0.70-1.16)$ & $0.70(0.49-0.99)^{*}$ \\
\hline No & 174 & 369 & 1,612 & & & & & & \\
\hline Yes & 175 & 528 & 1,839 & $1.51(1.21-1.89)^{*}$ & $0.92(0.83-1.02)$ & $1.26(1.01-1.58)^{*}$ & $0.89(0.79-0.99)^{*}$ & $1.49(1.17-1.91)^{*}$ & $0.85(0.59-1.22)$ \\
\hline No & 173 & 529 & 2,286 & & & & & & \\
\hline \multicolumn{10}{|l|}{ Insulin } \\
\hline Yes & 65 & 220 & 733 & $1.20(0.91-1.58)$ & $0.92(0.81-1.06)$ & $1.35(1.00-1.81)$ & $0.95(0.83-1.09)$ & $1.57(1.13-2.18)^{*}$ & $1.00(0.60-1.65)$ \\
\hline No & 283 & 837 & 3,391 & & & & & & \\
\hline \multicolumn{10}{|l|}{ Other GLDs } \\
\hline Yes & 47 & 220 & 705 & $0.77(0.56-1.06)$ & $0.94(0.78-1.13)$ & $0.95(0.68-1.31)$ & $0.91(0.75-1.10)$ & $1.00(0.69-1.46)$ & $0.93(0.53-1.62)$ \\
\hline No & 301 & 837 & 3,419 & & & & & & \\
\hline
\end{tabular}

${ }^{a}$ Model includes ever vs. never exposure to metformin, sulphonylurea derivatives (SU), insulin and other GLDs

${ }^{\mathrm{b}}$ Model includes cumulative exposure to metformin, SU, insulin and other GLDs per year and is additionally adjusted for ever vs. never exposure to metformin, SU, insulin and other GLDs

${ }^{\mathrm{c}}$ Model is adjusted for age at $\mathrm{BC}$ diagnosis, diabetes duration (years) before $\mathrm{BC}$, year of $\mathrm{BC}$ diagnosis, $\mathrm{BC}$ treatment (surgery, radiotherapy, chemotherapy, hormone therapy within 6 months after $\mathrm{BC}$ diagnosis), hormone replacement therapy prior to BC diagnosis (yes/no), comorbidity (stroke, chronic pulmonary disease, congestive heart disease, diabetes with complications, myocardial infarction, peptic ulcer disease, peripheral vascular disease, renal disease) prior to BC diagnosis (yes/no)

$*$ P-value $<0.05$ 
Table 3 The association between GLD use and breast cancer-specific and all-cause mortality among breast cancer patients with incident diabetes.

\begin{tabular}{|c|c|c|c|c|c|c|c|c|c|}
\hline & \multirow{3}{*}{$\begin{array}{l}\text { Nos. of } \\
\text { BC /all } \\
\text { deaths }\end{array}$} & \multirow{3}{*}{$\begin{array}{c}\text { Nos. } \\
\text { of } \\
\text { patients }\end{array}$} & \multirow{3}{*}{$\begin{array}{c}\text { Person } \\
\text { years }\end{array}$} & \multicolumn{2}{|c|}{ Unadjusted analyses } & \multicolumn{4}{|c|}{ Adjusted analyses } \\
\hline & & & & Ever vs. never ${ }^{a}$ & Per year of use ${ }^{b}$ & Ever vs. never ${ }^{\mathrm{a}, \mathrm{c}}$ & Per year of use ${ }^{b, c}$ & $\begin{array}{c}<2 \text { years use versus } \\
\text { none }^{c}\end{array}$ & $\begin{array}{c}>2 \text { years use versus } \\
\text { none }^{c}\end{array}$ \\
\hline & & & & HR $(95 \% \mathrm{CI})$ & $\operatorname{HR}(95 \% \mathrm{CI})$ & $\mathrm{HR}(95 \% \mathrm{CI})$ & $\mathrm{HR}(95 \% \mathrm{CI})$ & HR $(95 \% \mathrm{CI})$ & HR $(95 \% \mathrm{CI})$ \\
\hline \multicolumn{10}{|c|}{ Breast cancer-specific mortality } \\
\hline Metformin & & & & & & & & & \\
\hline Yes & 40 & 437 & 1,363 & $0.97(0.58-1.64)$ & $0.73(0.56-0.95)^{*}$ & $0.99(0.58-1.71)$ & $0.73(0.56-0.96)^{*}$ & $1.17(0.68-2.03)$ & $0.47(0.17-1.27)$ \\
\hline No & 28 & 269 & 1,063 & & & & & & \\
\hline \multicolumn{10}{|l|}{ SU } \\
\hline Yes & 33 & 210 & 578 & $3.41(2.07-5.64)^{*}$ & $0.85(0.65-1.12)$ & $3.15(1.87-5.30)^{*}$ & $0.88(0.66-1.16)$ & $3.51(2.04-6.06)^{*}$ & $3.51(1.31-9.36)^{*}$ \\
\hline No & 35 & 496 & 1,848 & & & & & & \\
\hline \multicolumn{10}{|l|}{ Insulin } \\
\hline Yes & 3 & 35 & 88 & $0.98(0.30-3.23)$ & $0.60(0.15-2.45)$ & $0.93(0.27-3.20)$ & $0.62(0.15-2.53)$ & $1.15(0.32-4.19)$ & - \\
\hline No & 65 & 671 & 2,338 & & & & & & \\
\hline \multicolumn{10}{|l|}{ Other GLDs } \\
\hline Yes & 4 & 74 & 232 & $0.42(0.14-1.23)$ & $1.94(1.01-3.70)^{*}$ & $0.40(0.13-1.17)$ & $1.52(0.78-2.95)$ & $0.35(0.08-1.49)$ & $0.61(0.13-2.91)$ \\
\hline No & 64 & 632 & 2,194 & & & & & & \\
\hline \multicolumn{10}{|c|}{ All-cause mortality } \\
\hline Metformin & & & & & & & & & \\
\hline Yes & 69 & 437 & 1,363 & $0.70(0.48-1.01)$ & $1.03(0.89-1.19)$ & $0.79(0.54-1.17)$ & $1.04(0.90-1.21)$ & $0.81(0.54-1.22)$ & $0.66(0.37-1.19)$ \\
\hline No & 65 & 269 & 1,063 & & & & & & \\
\hline \multicolumn{10}{|l|}{ SU } \\
\hline Yes & 56 & 210 & 578 & $2.71(1.88-3.92)^{*}$ & $1.01(0.85-1.19)$ & $2.50(1.71-3.66)^{*}$ & $0.98(0.83-1.16)$ & $2.60(1.73-3.91)^{*}$ & $2.15(1.11-4.16)^{*}$ \\
\hline No & 78 & 496 & 1,848 & & & & & & \\
\hline \multicolumn{10}{|l|}{ Insulin } \\
\hline Yes & 7 & 35 & 88 & $1.33(0.60-2.95)$ & $0.61(0.28-1.33)$ & $1.41(0.61-3.23)$ & $0.66(0.31-1.42)$ & $1.69(0.68-4.20)$ & $0.68(0.09-5.13)$ \\
\hline No & 127 & 671 & 2,338 & & & & & & \\
\hline \multicolumn{10}{|l|}{ Other GLDs } \\
\hline Yes & 9 & 74 & 232 & $0.51(0.25-1.07)$ & $0.99(0.61-1.59)$ & $0.53(0.25-1.11)$ & $0.90(0.56-1.44)$ & $0.62(0.27-1.42)$ & $0.31(0.07-1.39)$ \\
\hline No & 125 & 632 & 2,194 & & & & & & \\
\hline
\end{tabular}

${ }^{a}$ Model includes ever vs. never exposure to metformin, sulphonylurea derivatives (SU), insulin and other GLDs

${ }^{\mathrm{b}}$ Model includes cumulative exposure to metformin, SU, insulin and other GLDs per year and is additionally adjusted for ever vs. never exposure to metformin, SU, insulin and other GLDs

${ }^{\mathrm{c}}$ Model is additionally adjusted for age at $\mathrm{BC}$ diagnosis, year of $\mathrm{BC}$ diagnosis, $\mathrm{BC}$ treatment (surgery, radiotherapy, chemotherapy, hormone therapy within 6 months after $\mathrm{BC}$ diagnosis),

hormone replacement therapy prior to $\mathrm{BC}$ diagnosis (yes/no), comorbidity (stroke, chronic pulmonary disease, congestive heart disease, myocardial infarction, peptic ulcer disease, peripheral

vascular disease, renal disease) prior to $\mathrm{BC}$ diagnosis (yes/no)

$*$ P-value $<0.05$ 
Table 4 Sensitivity analyses assessing the association between GLD use and breast cancer-specific mortality among prevalent and incident diabetes patients

\begin{tabular}{|c|c|c|c|c|c|c|}
\hline & $\begin{array}{l}\text { Nos. of } \\
\text { BC deaths }\end{array}$ & $\begin{array}{l}\text { Nos. of } \\
\text { patients }\end{array}$ & $\begin{array}{c}\text { Metformin } \\
\text { Ever versus never } \\
\text { HR }(95 \% \mathrm{CI})\end{array}$ & $\begin{array}{c}\text { SU } \\
\text { Ever versus never } \\
\text { HR }(95 \% \mathrm{CI})\end{array}$ & $\begin{array}{c}\text { Insulin } \\
\text { Ever versus never } \\
\text { HR }(95 \% \mathrm{CI})\end{array}$ & $\begin{array}{c}\text { Other GLDs } \\
\text { Ever versus never } \\
\text { HR }(95 \% \mathrm{CI})\end{array}$ \\
\hline \multicolumn{7}{|l|}{ Prevalent diabetes patients $(\mathrm{n}=1057)$} \\
\hline Main ever never analysis (Table 2) ${ }^{a, b}$ & 150 & 1057 & $0.78(0.55-1.12)$ & $1.41(1.00-1.99)$ & $1.37(0.87-2.14)$ & $1.12(0.70-1.78)$ \\
\hline Analysis in patients with available stage $\mathrm{a}, \mathrm{b}$ & 57 & 410 & $0.90(0.52-1.55)$ & $1.38(0.80-2.40)$ & $1.01(0.50-2.04)$ & $1.25(0.62-2.50)$ \\
\hline Additionally adjusted for stage $\mathrm{a,b}$ & 57 & 410 & $0.96(0.53-1.75)$ & $1.76(0.99-3.14)$ & $1.33(0.61-2.90)$ & $1.44(0.69-2.97)$ \\
\hline Used a lag of 1 year instead of 6 months ${ }^{a, b}$ & 132 & 987 & $0.76(0.52-1.12)$ & $1.23(0.85-1.78)$ & $1.70(1.06-2.72)$ & $1.38(0.85-2.24)$ \\
\hline $\begin{array}{l}\text { Use of GLDs in } 6 \text { months after BC diagnosis } \\
\text { (not time varying) a }\end{array}$ & 150 & 1057 & $0.75(0.53-1.07)$ & $1.28(0.91-1.81)$ & $1.07(0.60-1.91)$ & $1.40(0.80-2.42)$ \\
\hline Case control analysis ${ }^{\mathrm{a}, \mathrm{d}}$ & & 1522 & $0.78(0.53-1.15)$ & $1.41(0.98-2.04)$ & $1.35(0.81-2.25)$ & $1.07(0.63-1.81)$ \\
\hline \multicolumn{7}{|l|}{ Incident diabetes patients (n=706) } \\
\hline Main ever never analysis (Table 3$)^{\mathrm{b}, \mathrm{c}}$ & 68 & 706 & $0.99(0.58-1.71)$ & $3.15(1.87-5.30)$ & $0.93(0.27-3.20)$ & $0.40(0.13-1.17)$ \\
\hline Analysis in patients with available stage $e^{b, c}$ & 38 & 348 & $0.87(0.41-1.83)$ & $3.72(1.84-7.51)$ & $0.97(0.13-7.41)$ & $0.18(0.02-1.37)$ \\
\hline Additionally adjusted for stage $\mathrm{b}^{\mathrm{b}, \mathrm{c}}$ & 38 & 348 & $0.93(0.45-1.95)$ & $2.80(1.34-5.87)$ & $0.56(0.06-5.37)$ & $0.18(0.02-1.39)$ \\
\hline Used a lag of 1 year instead of 6 months ${ }^{b, c}$ & 53 & 623 & $1.19(0.65-2.20)$ & $2.88(1.60-5.20)$ & $1.30(0.36-4.72)$ & $0.32(0.09-1.14)$ \\
\hline
\end{tabular}

Used a lag of 1 year instead of 6 months ${ }^{\text {b, }}$

year of $\mathrm{BC}$ diagnosis, $\mathrm{BC}$ treatment (surgery, radiotherapy, chemotherapy, hormone therapy within 6 months after BC diagnosis), hormone replacement therapy prior to BC diagnosis (yes/no),

comorbidity (stroke, chronic pulmonary disease, congestive heart disease, diabetes with complications, myocardial infarction, peptic ulcer disease, peripheral vascular disease, renal disease)

prior to BC diagnosis (yes/no)

${ }^{\mathrm{b}}$ Exposure to metformin, SUs, insulin and other GLDs were modelled as time varying covariates, where patients become exposed after the first prescription of the respective drug (i.e.

ever/never analysis)

${ }^{\mathrm{c}}$ Model includes exposure to metformin, SUs, insulin and other GLDs and are additionally adjusted for age at BC diagnosis, year of BC diagnosis, BC treatment (surgery, radiotherapy,

chemotherapy, hormone therapy within 6 months after BC diagnosis), hormone replacement therapy prior to BC diagnosis (yes/no), comorbidity (stroke, chronic pulmonary disease, congestive heart disease, myocardial infarction, peptic ulcer disease, peripheral vascular disease, renal disease) prior to BC diagnosis (yes/no)

${ }^{\mathrm{d}}$ OR and 95\% CIs presented. Among cases ( $\left.\mathrm{n}=149\right)$, 76 (51\%) used metformin, 77 (52\%) used SUs, 28 (19\%) used insulin and 24 (16\%) used other GLDs. Among controls (n=1373), 752

(55\%) used metformin, 587 (43\%) used SUs, 201 (15\%) used insulin and $189(14 \%)$ used other GLDs. 